\title{
Randomised controlled trial of growth effect of hydrocortisone in congenital adrenal hyperplasia
}

\author{
Ivani Novato Silva, Claudio Elias Kater, Cristiane de Freitas Cunha, Marcos Borato Viana
}

Federal University of Minas Gerais, Belo Horizonte, Brazil: Unit of Paediatric Endocrinology I N Silva

C F Cunha

Department of

Paediatrics

M B Viana

Department of Medicine, Federal

University of São

Paulo, Brazil

C E Kater

Correspondence to: Dr I N Silva,

Department of Paediatrics,

Faculty of Medicine, Federa

University of Minas Gerais,

Avenue Alfredo Balena 190,

30130-100 Belo

Horizonte, MG, Brazil.

Accepted 5 June 1997

\begin{abstract}
The influence of 15 or $25 \mathrm{mg} / \mathrm{m}^{2}$ of daily oral hydrocortisone with fludrocortisone $0.1 \mathrm{mg} / \mathrm{day}$ on growth and laboratory findings was evaluated in a prospective randomised crossover trial over 12 months in 26 children with 21-hydroxylase deficiency. Nine non-salt losers had fludrocortisone stopped for a further six month period. Height velocity was significantly decreased during treatment with $25 \mathrm{mg} / \mathrm{m}^{2}$ as compared with $15 \mathrm{mg} / \mathrm{m}^{2}$. This was the most sensitive indicator of corticosteroid treatment excess. A dose dependent effect upon plasma concentrations of 17hydroxyprogesterone, testosterone, and androstenedione was found but increased values were still detected in more than half of the determinations made during the 25 $\mathrm{mg} / \mathrm{m}^{2}$ period. Height velocity and 17hydroxyprogesterone concentrations were positively correlated. Growth hormone response to clonidine stimulation and insulin-like growth factor-1 concentrations were both within reference values and there was no difference between treatment periods. Withdrawal of fludrocortisone did not result in any difference for the non-salt losers. It was concluded that $25 \mathrm{mg} / \mathrm{m}^{2}$ of hydrocortisone depressed growth in children with congenital adrenal hyperplasia, and that full suppression, or even normalisation, of plasma concentrations of 17-hydroxyprogesterone and androgens should not be considered a treatment goal, but instead an indication of corticosteroid treatment excess.

(Arch Dis Child 1997;77:214-218)
\end{abstract}

Keywords: hydrocortisone; growth; congenital adrenal hyperplasia

Corticosteroids are successful as replacement treatment for children with congenital adrenal hyperplasia $(\mathrm{CAH})$. In 21-hydroxylase deficient children, electrolytes become normal and progression of virilisation is halted soon after treatment starts. Maintaining normal growth velocity remains a challenge, however. Long term follow up studies show that patients with $\mathrm{CAH}$ fail to achieve their predicted final heights. ${ }^{1-3}$ Growth impairment has been attributed to the various corticosteroid schedules employed. ${ }^{4}$ However, individual differences in treatment needs make this difficult to evaluate.

Hydrocortisone and cortisone are regarded as the glucocorticoids of choice in treating children with CAH because of presumed lesser growth suppression. ${ }^{5}$ The ideal treatment regi- men is not known, however. Recent reports have shown that the physiological cortisol secretion is significantly lower than previously accepted. $^{6-8}$ Accordingly, smaller glucocorticoid replacement doses have been proposed, ${ }^{9} 10$ but daily substitutive doses as high as $30 \mathrm{mg}$ of hydrocortisone $/ \mathrm{m}^{2}$ are sometimes recommended, particularly during the first two years of life. ${ }^{41}$

Although plasma concentrations of 17hydroxyprogesterone (17-OHP) and androgens are frequently used to monitor treatment, there is great variability in those concentrations, ${ }^{12}$ which hampers the usefulness of the tests.

We compared the short term effect of two hydrocortisone treatment doses on growth velocity and plasma concentrations of 17-OHP, testosterone, and androstenedione in children with 21-hydroxylase deficiency.

\section{Patients and methods}

We carried out a prospective randomised crossover trial for 12 months in 26 children (18 girls) with the classic form of $\mathrm{CAH}$ due to 21-hydroxylase deficiency. Their ages were 3.6 months to 15 years (median 45.3 months). They had been treated previously with hydrocortisone or prednisone for periods of three months to 14.5 years (median 38.5 months) before the trial began. Ages at diagnosis were 0 to 79 months (median 2.5).

None of the patients had reached final stature, with all estimates of bone maturity under 14 years (left wrist, Greulich and Pyle). Children were Tanner puberty stage I, except for four girls who were stages III or IV. ${ }^{13}$ Nutritional evaluation at the start of the follow up showed normal caloric and protein intake.

After a three month observation period while on their previous medication, all 26 children were randomised to receive either 15 or 25 $\mathrm{mg} / \mathrm{m}^{2}$ daily of oral hydrocortisone with fludrocortisone $0.1 \mathrm{mg} /$ day for six months and then had their dose schedule switched (crossover) for another six months. These doses represent the average and upper limit of what is usually recommended. The hydrocortisone was divided into three daily doses.

Nine of the 26 children were non-salt losers and had their fludrocortisone stopped for a further six months, to complete 18 months of follow up.

Each child was examined every three months by the same physician (who was unaware of the hydrocortisone schedule), to evaluate height, growth velocity, weight gain, and the presence of signs of virilisation and/or glucocorticoid excess. Physical examination focused on the 
appearance or increment of body hair and acne, deepening of the voice, abnormal weight gain, or changes in lean body mass as well as abnormal blood pressure and menstrual irregularities.

Morning fasting plasma concentrations of 17-OHP, testosterone, and androstenedione were determined at each visit, after the first hydrocortisone dose given at home. Patients were also submitted to a functional evaluation of growth hormone secretion, basal, and 75 minutes after oral clonidine $(0.15 \mathrm{mg} / \mathrm{kg})$. Plasma concentrations of insulin-like growth factor-1 (IGF-1) were determined at the end of each six month period.

Plasma samples were frozen at $-20^{\circ} \mathrm{C}$ for subsequent analysis. All plasma steroids and IGF-1 concentrations were assayed by standardised radioimmunoassay methods, ${ }^{14-17}$ and growth hormone was determined by an immunoenzymometric assay. ${ }^{18}$

After thorough explanation, all parents or legal guardians gave written informed consent to their children participating in the study.

\section{STATISTICAL METHODS}

Means of the differences of height for age and weight for age $\mathrm{z}$ scores between the beginning and the end of each treatment period were compared using the two tail paired Student's $t$ test. The National Center for Health Statistics standards were used as reference population indices. ${ }^{19}$ The possibility of a carryover effect of the first over the second hydrocortisone treatment period was evaluated by F statistics. ${ }^{20}$ The steroid and the growth hormone values for each period were represented by the mean of approximately 52 hormonal determinations (two for each of the 26 children). The paired Student's $t$ test was used for comparisons. Growth and plasma steroid determinations from the four pubertal girls were analysed separately. Rejection of the null hypothesis was set at $5 \%(\mathrm{p}<0.05)$.

\section{Results}

The mean height and weight $\mathrm{z}$ scores of the two randomised groups at the beginning of the trial were not significantly different.

Figure 1 shows the statural growth of the 22 initially prepubertal children during the two study periods. There was a significantly $(\mathrm{p}=0.02)$ greater increase in height while using $15 \mathrm{mg} / \mathrm{m}^{2}$ (mean $(\mathrm{SE}) \mathrm{z}$ score $=0.28(0.11)$ ) as compared with $25 \mathrm{mg} / \mathrm{m}^{2}(-0.06(0.12))$. Figure 1 also shows the statural growth of the whole group $(n=26)$. There was a similar pattern of growth with significant increases in height $(p=0.03)$ during the $15 \mathrm{mg} / \mathrm{m}^{2}$ hydrocortisone period $(\mathrm{z}$ score $=0.18(0.11))$ when compared with the $25 \mathrm{mg} / \mathrm{m}^{2}$ period $(-0.10$ (0.10)). Comparison of the statural growth during the two hydrocortisone dose schedules was possible due to a non-significant carryover effect $(p=0.63)$. Because this effect was significant for weight gain, the comparison was made only for the first six months of the trial, with no 


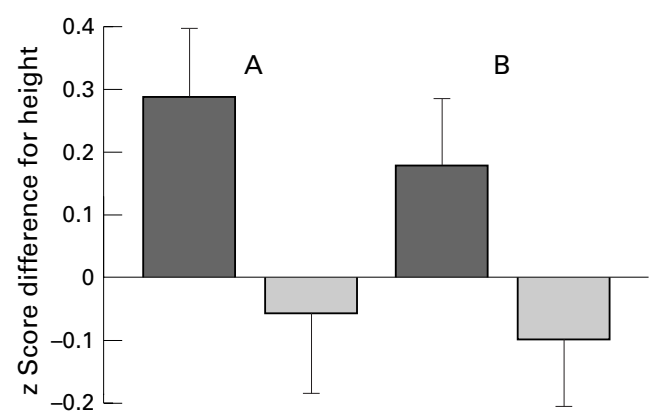

Hydrocortisone

$15 \mathrm{mg} / \mathrm{m}^{2} \square 25 \mathrm{mg} / \mathrm{m}^{2}$

Figure 1 Differences of height for age z scores (mean, SE) for $C A H$ children between the beginning and the end of each six month treatment period with hydrocortisone, 15 or $25 \mathrm{mg} / \mathrm{m}^{2}$ daily. (A) 22 children, excluding four pubertal girls; (B) all 26 children.

differences being detected $(0.15(0.54) v 0.02$ (0.57), respectively for the 15 and the 25 $\left.\mathrm{mg} / \mathrm{m}^{2}, \mathrm{p}=0.55\right)$.

Plasma steroid evaluation showed a variable pattern that was partially related to the hydrocortisone dosage (table 1). The most striking variations were observed for the four pubertal girls.

We observed dose dependent hydrocortisone suppression of plasma concentrations of 17 OHP and androstenedione for the 22 children. The lowest concentrations were associated with the $25 \mathrm{mg} / \mathrm{m}^{2}$ hydrocortisone dose (table 1). Testosterone concentrations did not change significantly.

Growth velocity and 17-OHP concentrations were positively correlated (fig 2). The regression line crosses the y axis (natural logarithms of $17-\mathrm{OHP}$ ) at 3.04 , indicating that optimal growth velocity ( $\mathrm{z}$ score difference $=$ zero) occurred with average plasma concentrations of $17-\mathrm{OHP}$ around $21 \mathrm{nmol} / 1$. We observed no such association with androgens. Peak and increment growth hormone secretion

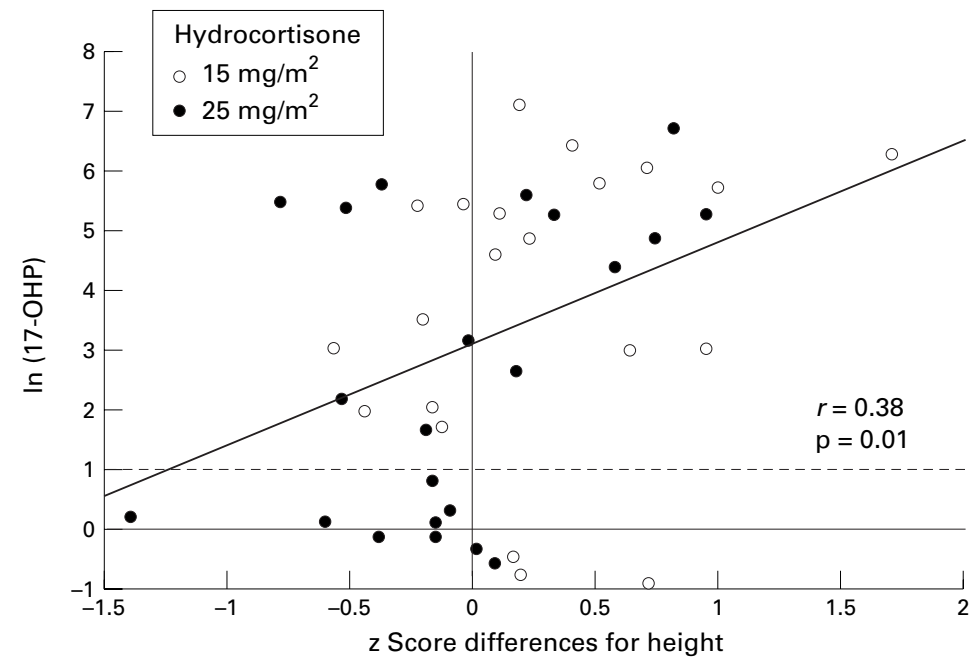

Figure 2 Correlation between 17-OHP values (natural logarithms) and height for age $z$ scores of $22 \mathrm{CAH}$ children after six months of treatment with hydrocortisone, 15 (open circles) or $25 \mathrm{mg} / \mathrm{m}^{2}$ (closed circles) daily. The diagonal line represents the regression curve and the horizontal dashed line the upper limit of the reference values. after clonidine stimulation and IGF-1 concentrations were not different in the two study periods (table 1 ).

No differences in height for age $(-0.23$ $(0.24)$ and $-0.20(0.22))$ or weight for age $(-0.04(0.45)$ and $-0.06(0.38)) \mathrm{z}$ scores were observed for the nine non-salt losers six months after discontinuation of fludrocortisone when compared with the previous six months (while on fludrocortisone and the same hydrocortisone dose). There were no difference in the laboratory data between these two periods.

We detected mild hypertension in two children $(8 \%)$ without renal or cardiac dysfunction. During follow up, blood pressure became normal in both. Hirsutism, acne, and weight gain were reported by one child $(5 \%)$ regardless of the hydrocortisone schedule being used.

Three girls out of the 22 children who began the study on Tanner's stage I reached stages II and III after six to 15 months. The four initially pubertal girls presented with menstrual irregularities.

\section{Discussion}

Many reports have shown poor height prognosis for $\mathrm{CAH}$ treated patients. Mean final heights achieved by 282 adults ranged from $\mathrm{z}$ score $=-0.67$ to $-2.2 .^{1-3} 5^{21-25}$ Several investigators have advocated reducing the hydrocortisone replacement dose, ${ }^{9}{ }^{10}$ mainly to increase final height by reducing any detrimental influence of pharmacological doses of corticosteroids on growth velocity.

Doses of corticosteroids which are even slightly supraphysiological during the first two years of life may compromise the accelerated growth velocity normal at this time. Absence of a later catch up would result in irreversible height impairment. ${ }^{1126}$

Although mineralocorticoids are recommended for all salt losers, their role in improving growth of non-salt losers is controversial. ${ }^{1027}$

Recent studies concerning adrenocortical production of cortisol showed that its physiological secretion rate is much lower ${ }^{6}$ than previously considered. ${ }^{28}$ Thus, children with $\mathrm{CAH}$ are possibly being given hydrocortisone in excess of their needs.

This limited term follow up of 26 children with $\mathrm{CAH}$ showed a significant decrease in growth velocity during the six month period of treatment with $25 \mathrm{mg}$ of hydrocortisone $/ \mathrm{m}^{2}$ as compared with the $15 \mathrm{mg} / \mathrm{m}^{2}$ dose period. These results indicate that doses of hydrocortisone in the upper limit of the frequently recommended range are not adequate.

Also remarkable was the fact that a decrease in growth velocity was the most sensitive clinical indicator of corticosteroid excess. Clinical signs of virilisation or hypercortisolism were rather scarce, if any, making recognition of drug excess difficult.

The present study was unable to show any relation between changes in growth hormone or IGF-1 and growth of children with CAH. 
Growth hormone response to clonidine stimulation and plasma concentrations of IGF-1 were both within laboratory reference values and no differences were detected between the two periods of hydrocortisone intake.

Withdrawal of fludrocortisone did not result in any significant difference in growth velocity or laboratory data for the nine children without clinical evidence of salt loss.

The absence of a reliable laboratory value for treatment monitoring is one of the main problems in the management of CAH. It is common sense that clinical follow up is the most efficient way to evaluate the adequacy of hydrocortisone replacement, ${ }^{29}$ but since it cannot reflect day to day changes it is agreed that a laboratory marker is needed for fine tuning of the dose schedules. ${ }^{410}$ So far, plasma concentrations of androstenedione are believed to be relatively stable and reliable for this purpose. ${ }^{30} 31$

In our study, however, we observed that even high doses of hydrocortisone $\left(25 \mathrm{mg} / \mathrm{m}^{2}\right)$ were unable to fully suppress or even normalise the adrenal production of 17-OHP and androgens. There was a dose dependent effect upon the plasma concentrations of these steroids, but increased values were still present in more than $50 \%$ of the determinations during the 25 $\mathrm{mg} / \mathrm{m}^{2}$ dose period. The steroid concentrations in late puberty were specially unresponsive to hydrocortisone treatment in current recommended doses.

Partial or incomplete adherence to the treatment regimen is often used to explain the variable steroid results in $\mathrm{CAH}$ treated patients. ${ }^{22}$ However, this seems unlikely in the present study because the effect of hydrocortisone intake on growth velocity was quite evident. In addition, the rhythmicity of adrenal steroid secretion $^{32}$ makes a single morning plasma sample an unreliable marker of the metabolic status of these children throughout a 24 hour period.

A positive relation between the plasma concentrations of 17-OHP, but not of androgens, and growth velocity was shown. It suggests that smaller hydrocortisone doses may be beneficial to growth. In a regression analysis we detected optimal growth velocity ( $\mathrm{z}$ score difference $=$ zero) in the presence of 17-OHP concentrations about seven times the reference values for children. We consider this observation should be taken into consideration in the follow up of children with $\mathrm{CAH}$.

Because of the trial design, generalisation for a better prognosis for final height cannot be inferred from our data.

It remains to be established whether and how the supranormal concentrations of androgens would affect bone age and ultimate growth. Though proposed, ${ }^{33}$ a specific adrenal androgen secretion controller has not yet been isolated.

Therefore, longer term follow up studies with lower doses of hydrocortisone are needed to evaluate the final height of patients with CAH.

We conclude that the current upper limit of hydrocortisone treatment doses for treating children with $\mathrm{CAH}$ is harmful to growth veloc- ity at least on short term follow up. Because hydrocortisone doses high enough to compromise growth do not necessarily suppress steroid overproduction, full suppression, or even normalisation, of 17-OHP and androgen plasma concentrations should be avoided. Normal laboratory values should not be considered a treatment goal, but instead an indication of excessive corticosteroid treatment in these patients.

We thank Dr Enrico Antonio Colosimo from the Department of Statistics, Federal University of Minas Gerias (Belo Horizonte), for helping with the statistical analysis.

1 DiMartino-Nardi J, Stoner E, O'Connell A, New MI. The effect of treatment on final height in classical congenital adrenal hyperplasia (CAH). Acta Endocrinol Suppl (Copenh) 1986;279:305-14.

2 Urban MD, Lee PA, Migeon CJ. Adult height and fertility in men with congenital virilizing adrenal hyperplasia. $N$ Engl f Med 1978;299:1392-6.

3 New MI, Gertner JM, Speiser PW, del Balzo P. Growth and final height in classical and nonclassical 21-hydroxylase deficiency. Acta Paediatr fpn 1988;30(suppl):79-88.

4 New MI. Female pseudohermaphroditism. Semin Perinatol 1992; 16:299-318.

5 Styne DM, Richards GE, Bell JJ, et al. Growth patterns in congenital adrenal hyperplasia. Correlation of glucocorticoid therapy with stature. In: Lee PA, Plotnik LP, Kowarski AA, et al, eds. Congenital adrenal hyperplasia. Baltimore: University Park Press, 1977:247-63.

6 Linder BL, Esteban NV, Yergey AL, Winterer JC, Loriaux DL, Cassorla F. Cortisol production rate in childhood and adolescence. F Pediatr 1990;117:892-6.

7 Esteban NV, Yergey AL. Cortisol production rates measured by liquid chromatography/mass spectrometry. Steroids 1990;55:152-8.

8 Kerrigan JR, Veldhuis JD, Leyo SA, Iranmanesh A, Rogol

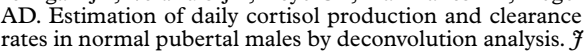
Clin Endocrinol Metab 1993;76:1505-10.

9 Hughes LA. Management of congenital adrenal hyperplasia. Arch Dis Child 1988;63:1399-404.

10 Miller WL. Genetics, diagnosis, and management of 21-hydroxylase deficiency (clinical review). f Clin Endocrinol Metab 1994;78:241-5.

11 Rasat R, Espiner EA, Abbott GD. Growth patterns and outcomes in congenital adrenal hyperplasia; effect of chronic treatment regimens. $N Z$ Med $\mathscr{f}$ 1995;108:311-4.

12 Silva IN, Oliveira Jr DF, Simal CJR, Viana MB, Chagas AJ. Morning steroid profile in children with congenital adrenal hyperplasia under different hydrocortisone schedules. Indian f Pediatr 1994;61:341-6.

13 Marshall WA, Tanner JM. Variations in pattern of pubertal changes in girls. Arch Dis Child 1969;44:291-303.

14 Vieira JGH, Russo EMK, Maciel RMB, Germek OA, Verreschi ITN. Radioimunoensaio da 17-alfa-hidroxiprogesterona no soro: considerações metodológicas. Arq Bras Endocrinol Metabol 1980;24:24-30.

15 Lox CD, Christian MD, Heine MW. A simple radioimmunoassay for testosterone. Am f Obstet Gynecol 1974;118: $114-9$.

6 Vieira JGH, Russo EMK, Maciel RMB, Germek OA. Desenvolvimento de um método radioimunológico simples para a dosagem de androstenediona no soro. Arq Bras Endocrinol Metabol 1981;25:47-50.

17 Underwood LE, Murphy MG. Radioimmunoassay of the somatomedins/insulin-like growth factors. In: Patrano C, Peskar BA, eds. Radioimmunoassay in basic and clinical pharmacology. Berlin: Springer-Verlag 1987:561-74.

18 Vieira JGH, Lombardi MT, Nishida SK. Monoclonal antibody-based immunoenzymometric assay for human antibody-based immunoenzymometric assay for humar hormone. Braz f Med Biol Res 1990;23:293-6.

19 Hamil PVV, Drizd TA, Johnson CL, Reed RB, Roche AF, Moore WM. Physical growth: National Center for Health Moore WM. Physical growth: National Center for He

20 Jones B, Kenward MG. The $2^{\star} 2$ cross-over trial with continuous data. In: Jones B, Kenward MG, eds. Design and analysis of cross-over trials. London: Chapman and Hall, 1989:16-84

21 Klingensmith GJ, Garcia SC, Jones HW, Migeon JC, Blizzard RM. Glucocorticoid treatment of girls with congenital adrenal hyperplasia: effects on height, sexual maturation, and fertility. $\mathcal{F}$ Pediatr 1977;90:996-1004

22 Migeon CJ, Donohoue PA. Congenital adrenal hyperplasia caused by 21 -hydroxylase deficiency. Its molecular basis and its remaining therapeutic problems. Endocrinol Metab Clin North Am 1991;20:277-97.

23 Sandrini R, Jospe N, Migeon CJ. Temporal and individual variations in the dose of glucocorticoid used for the treatment of salt-losing congenital virilizing adrenal hyperplasia due to 21-hydroxylase deficiency. Acta Paediatr Suppl 1993;388:56-60. 
24 Young MC, Ribeiro J, Hughes IA. Growth and body proportions in proportions in congen
Child $1989 ; 64: 1554-8$.

25 Van der Kamp HJ, Slijper FME, Brandenburg H, de Muink Keizer-Schrama SMPF, Drop SLS, Molenaar JC. Evaluation of young women with congenital adrenal hyperplasia: a pilot study. Horm Res 1992;37(suppl 3):45-9.

26 Sperling MA, Kenny FM, Schutt-Aine JC, Drash AL Linear growth and growth hormonal responsiveness in treated congenital adrenal hyperplasia. Am $\mathcal{F}$ Dis Child 1971;122:408-13.

27 Kuhnle U, Rosler A, Pareira JA, Gunzcler P, Levine LS , New MI. The effects of long-term normalization of sodium balance on linear growth in disorders with aldosterone deficiency. Acta Endocrinol 1983;102:577-82.

28 Kenny FM, Preeyasombat C, Migeon CJ. Cortisol production rate II. Normal infants, children and adults. Pediatrics 1966;37:34-42.
29 Appan S, Hindmarsh PC, Brook CGD. Monitoring treatment in congenital adrenal hyperplasia. Arch Dis Child 1989;64:1235-9.

30 Korth-Schutz S, Virdis R, Saenger P, Chow DM, Levine LS, New MI. Serum androgens as a continuing index of adequacy of treatment of congenital adrenal hyperplasia. $\mathcal{F}$ Clin Endocrinol Metab 1978;46:452-8.

31 Cavallo A, Corn C, Bryan GT, Meyer WJ. The use of plasma androstenedione in monitoring therapy of patients with congenital adrenal hyperplasia. F Pediatr 1979;95:337.

32 Frisch H, Parth K, Schober E, Swoboda W. Circadian patterns of plasma cortisol, 17-hydroxyprogesterone, and testosterone in congenital adrenal hyperplasia. Arch Dis Child 1981;56:208-13.

33 Parker LN. Control of adrenal androgen secretion. In: Parker LN, ed. Adrenal androgens in clinical medicine. San Diego: Academic Press, 1989:30-57. 